University of Wollongong

Research Online

Faculty of Law, Humanities and the Arts Papers (Archive)

Faculty of Arts, Social Sciences \& Humanities

$1-1-2017$

\title{
A case for a pan-Indian Ocean information grid for improved maritime domain awareness
}

Shishir Upadhyaya

University of Wollongong, su706@uowmail.edu.au

Follow this and additional works at: https://ro.uow.edu.au/lhapapers

Part of the Arts and Humanities Commons, and the Law Commons

Research Online is the open access institutional repository for the University of Wollongong. For further information contact the UOW Library: research-pubs@uow.edu.au 


\title{
A case for a pan-Indian Ocean information grid for improved maritime domain awareness
}

\author{
Abstract \\ The Indian Ocean region, in recent years, has witnessed a proliferation of information centers which have \\ emerged in response to various sub-regional requirements and sometimes representing diverse interest \\ groups. This paper highlights the gaps in regional maritime domain awareness (MDA) and argues that the \\ multiple disparate information systems have not contributed to improving overall maritime safety and \\ security in the Indian Ocean region. It puts forward a case for a pan-Indian Ocean information grid that \\ could integrate the various information sources to provide comprehensive MDA for the region.

\section{Disciplines} \\ Arts and Humanities | Law

\section{Publication Details} \\ Upadhyaya, S. (2017). A case for a pan-Indian Ocean information grid for improved maritime domain \\ awareness. Journal of the Indian Ocean Region, 13 (3), 335-354.
}




\section{A Case for a Pan-Indian Ocean Information Grid for Improved Maritime Domain Awareness}

\section{Shishir Upadhyaya}

Abstract: The Indian Ocean region, in recent years, has witnessed a proliferation of information centres which have emerged in response to various sub-regional requirements and sometimes representing diverse interest groups. This paper highlights the gaps in regional maritime domain awareness and argues that the multiple disparate information systems have not contributed to improving overall maritime safety and security in the Indian Ocean region. It puts forward a case for a pan-Indian Ocean Information Grid that could integrate the various information sources to provide comprehensive MDA for the region.

\section{Introduction}

The commissioning of a maritime information fusion centre at Madagascar in 2015 marks the latest addition to the Indian Ocean region's directory of information centres. Other such facilities for monitoring shipping, set up not so long ago, also include centres at Yemen, Kenya and Tanzania. The mushrooming of information centres in the region clearly indicates a continued focus on maritime affairs on the part of littoral states. But, have these developments led to improved maritime domain awareness (MDA) within the Indian Ocean region? Evidently not, as MDA is not just limited to monitoring vessel movements, but encompasses a much wider sphere. MDA, as defined by the United States Navy document titled Navy Maritime Domain Awareness Concept, is the "effective understanding of anything associated with the maritime domain that could impact the security, safety, economy, or environment" of a state or region (USN, 2007, p. 3). The Indian maritime doctrine of 2016 provides a much narrower definition of MDA as, "being cognisant of the position and intentions of all actors, whether own, hostile or neutral, in the constantly evolving maritime environment in the areas of interest (IMD, 2016, p. 34)." Broadly, MDA consist of two components, "situational awareness," based on what is "observable and known," and "threat awareness," based on what is "anticipated or suspected" (USN, 2007, pp. 3- 
5). Thus, MDA is a state of comprehensive knowledge of the maritime domain, in near real time and continually maintained, a goal that states can only aspire to achieve but never fulfill. States, at best, can aspire to maintain a credible level of "situational awareness" and "threat warning" in their areas of interest for limited periods of time. Furthermore, MDA is largely unique to each state and although it may contain parts that could be common to other states or "shareable," the rest could be of a classified nature which states conscientiously guard. For instance, movements of crucial cargo such as oil into their own ports, is of strategic importance to all states. Similarly, private shipping companies may have commercial interests in not sharing movements of their ships contracted to load cargo, with their competitors. Even movements of fishing fleets to fishing grounds is valuable commercial intelligence. However, information such as meteorological reports in various parts of the ocean including tsunami warnings and accidents at sea including ship collisions that could lead to oil spills are easily "shareable."

This paper posits that the proliferation of new information centres in the Indian Ocean region has not effectively translated into improved MDA within the region, as each information centre represents only a small piece of the big MDA "zigsaw." The aim of this paper is to highlight the lack of synergy amongst various information centres in the Indian Ocean region leading to a duplication of efforts without commensurate enhancement of overall MDA. It proposes an integrated structure linking the multiple information centres into one information grid or a panIndian Ocean Information Grid that could provide a common maritime picture and related services accessible to all littoral states on similar lines as the European Maritime Safety Authority (EMSA). This, could perhaps be the first step in a bottom up approach to integrate the various sub-regional institutions within the Indian Ocean region, leading to greater synergy of regional efforts something which the regional organisations such as the Indian Ocean Naval Symposium and the Indian Ocean Rim Association have been seeking to achieve. This paper provides an assessment of the regional environment and discusses the genesis of various information centres established in the Indian Ocean region, followed by an examination of the extant facilities in the region. It highlights some key benefits of a pan-Indian Ocean information grid and examines the possibility of achieving it by integrating various maritime agencies and information systems as achieved by the EMSA. 


\section{Regional Environment}

The 21st century environment in the Indian Ocean region is a complex interplay of several factors, predominantly: the unique geography of the region with various choke points; an abundance of strategic natural resources which has boosted maritime trade; widespread disparities in development levels of the littoral states; and a lack of adequate maritime capacity amongst the majority of the regional states to manage their maritime affairs. Thus, the Indian Ocean region has witnessed a wide range of threats and challenges including piracy, smuggling, illegal fishing and similar transnational crimes at the lower end of the spectrum, to maritime terrorism and natural disasters at the higher end. Certain events of the early 21 st century, such as the maritime terrorist attacks in Aden involving the USS Cole and the French tanker Limburg in 2000 and 2002 respectively, armed attacks on ships in the Straits of Malacca and piracy off Somalia, and the 2004 Indian Ocean tsunami which killed over 226,408 people (Guha, Hoyois \& Below, 2015, pp. 1-2) exposed the region's vulnerability to various non-traditional threats. As there was no multilateral regional security forum to address the emerging maritime challenges of the time, the urgent requirements to combat the security threats led to the rise of several subregional organisations, such as the Malacca Strait security initiative, the International Maritime Bureau Piracy Reporting Centre (IMB PRC) of the International Chamber of Commerce (ICC), the Regional Cooperation Agreement on Combating Piracy and Armed Robbery against Ships in Asia (ReCAAP), and the Djibouti Code of Conduct. The common nature of non-traditional threats in the region in general, also seems to have encouraged a corralling of the regional states into an overarching regional naval forum, the Indian Ocean Naval Symposium, the only other regional organisation since the founding of the Indian Ocean Rim Association in the late 1990s. However, notwithstanding a move within the region to address the maritime challenges multilaterally, a comprehensive security regime for the Indian Ocean region is yet to evolve. This may be attributed to several factors notably, a lack of cohesion amongst the sub-regional groupings and the perceived dominant role of India with aspirations to emerge as the primary "net provider of security" for the Indian Ocean region, an approach that could restrict multilateralism.

As a result of the above factors, many of the regional security issues continue to be addressed at the sub-regional level by the affected states or relevant stakeholders. While the sub-regional 
institutions seem to have worked well, there is clearly a duplication of effort and lack of collaboration in several areas. For instance, over the years most sub-regional organisations have set up their own information centre carrying out similar functions related to monitoring of shipping traffic. In Southeast Asia, both, the IMB PRC setup in 1992 in Malaysia and the Information Sharing Centre (ISC) of the ReCAAP established at Singapore in 2006 track piracy and armed attacks on ships. The former represents the shipping industry or the commercial interests under the commercial crime services division of the ICC while the later was a Japanese initiative, signifying extra-regional interests. Moreover, all the newly established information centres of the Indian Ocean region function in addition to earlier global and regional information systems such as the international system for search and rescue (SAR) at sea, which includes several rescue coordination centres (RCCs) and the Indian Ocean Memorandum of Understanding on Port State Control, which links most Indian Ocean ports. Given that each of the new information centres were created at different periods of time, in response to specific requirements and representing various interest groups or stakeholders in the Indian Ocean region, they continue to function independently with limited coordination. Consequently, the proliferation of independent information centres in the region has not achieved commensurate improvement in maritime situational awareness within the whole region.

\section{Information Systems in the Indian Ocean Region}

Presently, several information systems exist in the Indian Ocean region including a few international mechanisms, developed in response to specific global maritime challenges, predating most sub-regional institutions. The various systems presently in force are discussed in this section.

\section{International System for Search and Rescue (SAR) Operations}

Until the adoption of the SAR Convention in 1979, there was no international system for search and rescue operations at sea. While there were certain areas that were covered by a well- 
established organisation for providing prompt and efficient assistance, many large parts of the world oceans had nothing at all. Following the adoption of the SAR Convention in April 1979, the IMO's Maritime Safety Committee divided the world's oceans into 13 search and rescue areas (SRA). Each SRA was further divided into multiple search and rescue regions (SARR) with earmarked states being accorded responsibilities for adjoining SARRs (SAR Convention, 1979). The SARRs for the Indian Ocean were finalised at the SAR conference held at Freemantle, Australia in 1998 (IMO, 2017).

In 1998, the SAR convention was revised with the aim of emphasising a regional approach to SAR operations and encourage co-ordination between maritime and aeronautical SAR operations. Concurrently with this revision, the IMO and the International Civil Aviation Organization jointly promulgated the International Aeronautical and Maritime Search and Rescue Manual.

In 1999, in line with developments in digital and satellite communication technology, the global maritime distress and safety system (GMDSS) was developed by the IMO in order to streamline the global radio and satellite communication network, so that, regardless of where a ship was in distress, help could be dispatched. GMDSS was introduced as an amendment to the International Convention for the Safety of Life at Sea (SOLAS) convention, Chapter IV, dealing with Radiocommunications. Under the GMDSS, all passenger vessels and cargo ships over 300 gross tonnages, are mandated to carry specified satellite and radio-communication equipment, for sending and receiving distress alerts and maritime safety information, and for general communications (IMO, 1999). The implementation of the GMDSS is regarded as a key milestone in maritime history and a massive achievement in ensuring the safety of seafarer's lives.

As noted earlier, the responsibility for SAR operations in each SARR of the world is entrusted to one of the regional states. The relevant state is required to set up national systems and arrangements such as Rescue Co-ordination Centres (RCC) and Rescue Sub-Centres (RSC), SAR facilities and communications in the area, including detailed plans for conducting SAR operations. For instance, India is responsible for search and rescue operations in the Bay of Bengal and the Andaman Sea region for which the Indian government has set up a RCC located at Port Blair. Australia has the largest SRR in the Indian Ocean spanning about 52.8 million 
square kilometres or over one-tenth of the earth's surface (AMSA, 2017). The various SARRs in the Indian Ocean are shown in the map below:

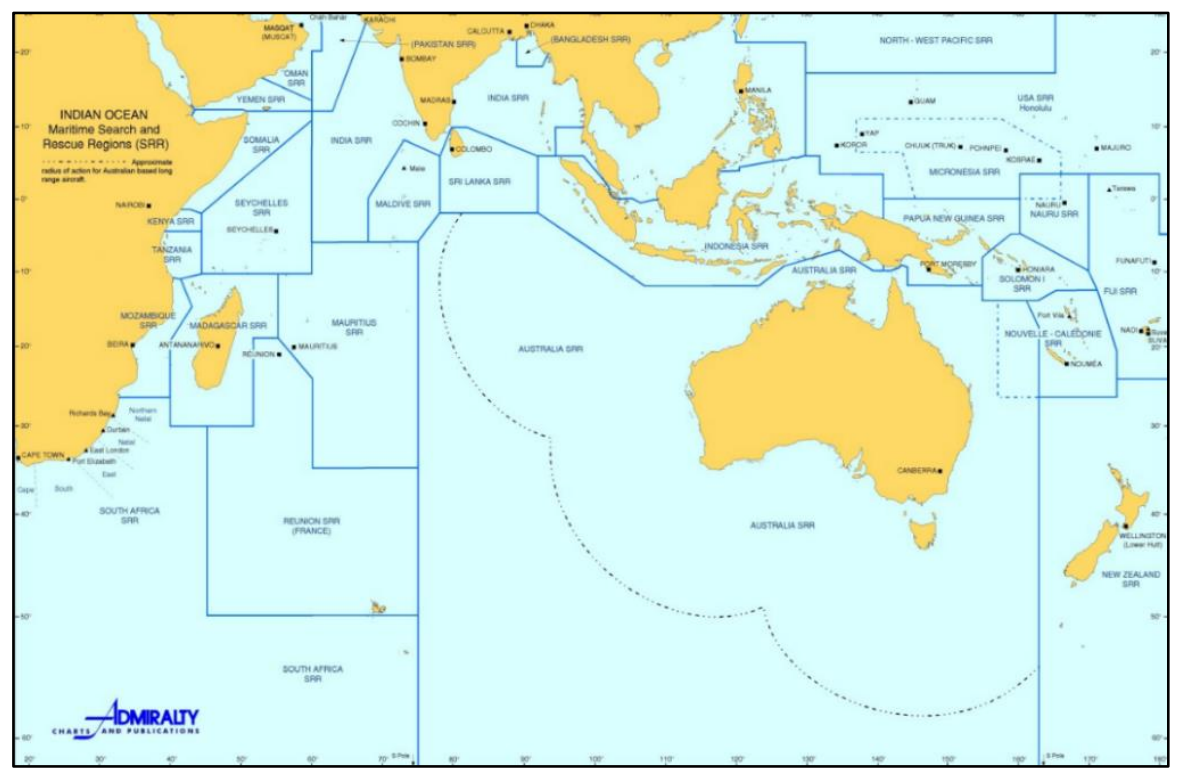

Source: Australian Maritime Safety Authority

It is clear from the above that coordination between various agencies and regional states is the key to successful SAR operations and the SAR convention emphasising cooperation between states expresses this as follows:

...unless otherwise agreed between the States concerned, a Party should authorize, subject to applicable national laws, rules and regulations, immediate entry into or over its territorial sea or territory for rescue units of other Parties solely for the purpose of search and rescue (SAR Convention, 1979).

Successful SAR operations are also dependent on the capacity of the concerned states in terms of surveillance assets such as ships, aircraft, satellites and underwater systems. In the Indian Ocean, a majority of the littoral states lack surveillance assets and equipment for SAR operations with just a handful being able to undertake SAR operations in the high seas (Sakhuja, 2014). Thus, as evident from the size of the SARR in the map above, a large burden of responsibility in the Indian Ocean region is shouldered by a few states, notably Australia and India. This gap in regional capacity was exposed in the SAR operations launched following the loss of the Malaysian Airlines flight MH 370 that disappeared in the Indian Ocean in March 2014. 
Inadequate capacity for SAR can complicate issues in times of crises. For instance, apparent gaps in satellite and radar inputs related to the flight path of the ill-fated plane provided by Malaysia to the Chinese government gave rise to mutual suspicions and skepticism (Bremner, 2015, pp. 812).

The mystery surrounding the loss of the plane remains unresolved to date. In the wake of the $\mathrm{MH}$ 370 incident, the ASEAN Regional Forum issued a statement, which called "for regional countries to strengthen SAR coordination and cooperation at bilateral, regional and multilateral levels, including through dialogue and cooperation in ARF" (CSCAP, 2016, p.2). Furthermore, the need to build regional SAR capability and improve cooperation and coordination amongst the regional states was also highlighted by the IORA in the Perth Communique of October 2014 (IORA, 2017).

Given the increased focus of Indian Ocean states on development of the blue economy which includes marine tourism, and given increases in air and shipping traffic in the Indian Ocean region, SAR related activities are likely to remain a high priority for all the regional states. While a global organisation for distribution of responsibility and communications is already in place, regional efforts to promote best practices, share technical and operational information such as drift modelling prediction and tracking are areas for regional cooperation. This presents an opportunity for regional cooperation in information sharing that could also serve as a driver for the development of the pan-Indian Ocean information grid.

\section{World-Wide Navigational Warning Service}

The Worldwide Navigational Warning Service (WWNWS) was established on 1 January 1977 through the International Hydrographic Organisation and the IMO, as an internationally coordinated broadcast service for promulgation of information on worldwide hazards to navigation for shipping. Under the WWNWS, the world is divided into 21 navigation areas or NAVAREAS, each under a designated coordinator responsible for collation and assessment of relevant information from various sources, followed by the drafting and broadcast of navigational warnings. The Indian Ocean is covered by NAVAREAS VII to XI, under South Africa, India, 
Pakistan, Australia and Japan, respectively. In 1999, following the implementation of the GMDSS, a maritime safety information (MSI) service was introduced to augment the WWNWS (IMO, 2017). The MSI is a system of internationally and nationally coordinated network of broadcasts, containing information which is necessary for safe navigation. It includes navigational warnings, meteorological information, SAR reports and other safety information. Under the MSI service, navigational warning and other messages are transmitted by satellite (NAVTEX) and radio (SafetyNET). Over the years, the MSI has improved and evolved as a highly reliable and effective system of providing information to the mariners at sea. However, the weak link in the entire system remains the collection of up to date information. Clearly, for the MSI system to be successful, the NAVAREA coordinators must receive latest information pertaining to navigational hazards from multiple sources covering the entire ocean. However, within the Indian Ocean region, several littoral states lack surveillance capacity, and thus potential hazards to shipping in large parts of the region remain unreported. For instance, in 2011, MV Pavit, a Panama flagged oil tanker carrying over 10 tonnes of fuel oil, drifted from Ras-AlMadrakah in Oman across hundreds of miles in the Arabian Sea following engine failure and flooding of its engine room, finally running aground at Mumbai in India (NDTV, 2011). Apparently, the ship owners were under the impression that the ship had been sunk while in reality the vessel drifted as a derelict across the busy shipping lanes of the western Indian Ocean for several days unobserved!

A pan-Indian Ocean information grid could help to improve surveillance and by linking the NAVAREA coordinators to the information grid, the extant mechanism for receiving latest information on navigational hazards could be significantly enhanced.

\section{Automatic Identification System (AIS)}

The AIS was brought into force by the IMO on 31 December 2004 under Chapter V, Annex 17 of the SOLAS convention, as a mechanism primarily aimed at enhancing safety of life at sea, the safety and efficiency of navigation, and the protection of the marine environment (IMO, 2017). The IMO defines AIS as a ship and shore-based broadcast system, operating in the VHF maritime 
band, designed to be capable of providing information about the ship to other ships and to coastal authorities automatically. IMO regulations require that AIS comply as follows:

- Provide information - including the ship's identity, type, position, course, speed, navigational status and other safety-related information - automatically to appropriately equipped shore stations, other ships and aircraft;

- Receive automatically such information from similarly fitted ships; · monitor and track ships;

- Exchange data with shore-based facilities (IMO, 2017).

There are two types of AIS, Classes "A" and "B." Class "A" AIS is mandated for vessels of 300 gross tonnage and upwards engaged on international voyages, cargo ships of 500 gross tonnage and upwards not engaged on international voyages and passenger ships, irrespective of size, which carry more than 12 passengers (IMO, 2017). All other smaller vessels such as pleasure craft may host AIS Class "B," but this is dependent upon the rules of the coastal state or national, sub-state or regional regulatory authority for particular vessels. It is not required by international regulation.

Considering the limitations in range of VHF based AIS, and with a view to promote ship reporting systems, the IMO introduced long range identification and tracking (LRIT) using satellite communication. LRIT was officially implemented on 1 July 2009. It is a system requiring vessels to automatically transmit their identity, position and the date/time every six hours via satellite links. The United States has been a key proponent of satellite AIS, prompted by concerns of maritime terrorism and the proliferation of weapons of mass destruction. However, given the "political sensitivities" (Rahman, 2007, p. 184) involved in unrestricted sharing of vessel positional data states, the IMO has restricted the access to satellite AIS data to Flag states in respect of their vessels, with SOLAS contracting governments bearing the related costs. However, this restriction is now redundant with the availability of AIS data commercially.

Over the years, as a result of commercial interests and maritime security challenges in the environment, the AIS has evolved into a versatile and popular tool for tracking ships globally, and is widely used by security organisations and commercial agencies alike, with several 
companies such as Lloyds List Intelligence and Marine Traffic providing global AIS data obtained from private terrestrial stations and satellites. The IMO has officially condemned public display of such AIS information by websites such as marinetraffic.com, noting that it could compromise ship security (AMSA, 2017). Furthermore, IMO guidelines allow Masters of vessels to exercise the option of switching off onboard AIS if they feel that continual operation may compromise ships' safety and security (AMSA, 2017). However, the demand for ship tracking services by ship and port agents, bunkering agents, commodity traders, port authorities, banks (which finance global trade) and even government security agencies has led to a spurt in companies providing global AIS information services for a price. Integration of commercial intelligence in to the regional information grid could be another useful measure to ensure comprehensive coverage of maritime trade.

\section{The Intergovernmental Coordination Group for the Indian Ocean Tsunami Warning and Mitigation System (IOTWS)}

This agency was formed in response to the Indian Ocean tsunami of December 2004, in which about 250,000 lives were lost in various littoral states around the Indian Ocean rim. The IOTWS was formed under the aegis of the UNESCO's Intergovernmental Oceanographic Commission (IOC/UNESCO) and is linked with the Pacific Tsunami Warning Centre (PWTC) and Japan's Meteorological Agency (JMA) (IOTWS, 2017). The IOTWS has 28 members from the Indian Ocean region including Australia, India and Indonesia, which are the three primary sources for tsunami advisories. In India, the Indian National Centre for Ocean Information Services (INCOIS) is the lead agency responsible for providing tsunami warnings (INCOIS, 2017). Similarly, the lead meteorological agency in each country is connected to the IOTWS. Thus, by being linked to all the apex meteorological agencies in the Indian Ocean region, the IOTIC, besides providing tsunami warnings, is also a rich source of a wide range of meteorological services and climatic information such as cyclone warning and storm surges. The IOTWS provides tsunami warning bulletins and conducts several training programmes and exercises for member states to deal with tsunamis. However, there is no indication of any engagement between IOTWS with the IORA or the IONS under which HADR is a key priority. By linking the 
IOTWS to the various information centres and through them, all the regional navies and coast guards, the entire region could be better prepared to deal with HADR operations.

\section{Indian Ocean Tuna Commission (IOTC)}

This is an important albeit low profile intergovernmental organisation responsible for the management, conservation and sustainable development of tuna and tuna-like species in the Indian Ocean. The IOTC is open for all Indian Ocean regional states and other states with an interest in fishing in the Indian Ocean. Currently, the IOTC has 31 members including 23 Indian Ocean rim states and 8 others including China, Japan and the E.U (IOTC, 2017). Broadly the charter of IOTC is to ensure conservation and optimum utilisation of the fish stocks in the Indian Ocean for long term sustainability. The IOTC is thus mandated to monitor illegal, unreported and unregulated (IUU) fishing activities in the Indian Ocean region and also monitor fishing vessels operating in the region (IOTC, 2017).

IUU fishing is a major maritime challenge in the Indian Ocean and pertinently the emergence of piracy off Somalia, in the early 21 st century, was directly related to IUU fishing in the Somali waters. The unchecked rise in IUU fishing in the Indian Ocean over the past several years that has led to several key fish stocks such as the Yellow-fin Tuna, having declined to below minimum sustainable levels, which indicates that the IOTC has not performed its duties as envisaged. In 2013, a Greenpeace International mission spent two months in the Indian Ocean documenting and exposing many loopholes in fisheries management and illegal fishing practices, and presented its findings to the IOTC. However, reportedly the organisation did not pay any attention to the report, and Greenpeace condemned IOTC for failing to prevent decline of the region's most vulnerable tuna species and its inability to undertake adequate measures to protect sharks (Greenpeace International, 2013).

Manifestly, IOTC is constrained by capacity to monitor the entire Indian Ocean region and keep track of fishing activities, a formidable task even for the regional coast guards and navies. Furthermore, several regulatory actions by the IOTC, such as boarding and inspecting fishing vessels, also fall under port state control and flag state control duties, an area where the Indian 
Ocean region states have a poor record (Bateman, 2012, pp.188.201). In contrast, the South Pacific Regional Fisheries Management Organisation (SPRFMO), set up in 2006 by Australia, Chile and New Zealand, and the Western and Central Pacific Fisheries Commission (WCPFC) established in 2004, have achieved significant success in curbing IUU fishing in the Pacific Ocean. The WCPFC has successfully implemented effective Vessel Monitoring System (VMS) for keeping track of fishing activities in the region, including maintaining an updated database of annual fish catch for various species (WCPFC, 2017). Under the VMS, all fishing vessels are required to install a position transmitter that enables officials to ensure compliance with area closures and other restrictions. The WCPFC also works in close collaboration with the regional navies and coast guards, which conduct boarding and inspections of fishing vessels and help to reinforce the VMS.

The IOTC has not been able to implement a VMS for the Indian Ocean region. It has also not been able to institutionalise a mechanism for operational level interaction with the regional coast guards and navies. Evidently IOTC could function more effectively by working in close collaboration with the two key regional institutions namely the Indian Ocean Naval Symposium and the Indian Ocean Rim Association, which have an overall responsibility for regional maritime security of which IUU is a sub-set and an area of common interest to all member states. Since the IOTC does not seem to have any institutionalised interaction with either of the above two organisations nor any of the maritime security agencies; by linking it to the regional institutions via the pan-Indian Ocean information grid, an Indian Ocean VMS could become a viable option supported by various regional maritime agencies.

\section{Indian Ocean Memorandum of Understanding on Port State Control (IOMOU)}

An idea for regional cooperation within the Indian Ocean rim states to control movements of substandard ships in the region was first mooted by India in 1997. Subsequent efforts by the IMO with support from the government of India (India hosted the preparatory meeting for the MoU and set up a Secretariat for the organisation at Goa) led to the drafting of a MoU for a Port State Control (PSC). PSC is a mechanism by which states inspect ships calling at their ports to ensure that sub-standard ships (ships that do not comply with required IMO environmental regulations, 
and international standards of safety and seamanship) do no operate in the region. Sub-standard ships are not only vulnerable to piracy/ armed attacks but also pose a threat to safety of crew and the environment and are more likely to participate in crimes (Bateman, 2012, p. 189). The MoU came into force in April 1999 and initial signatories of the IOMOU included Australia, Eritrea, India, Sudan, South Africa and Tanzania (IOMOU, 2017). As of December 2015, 17 Indian Ocean states have become parties to the IOMOU including; Australia, Bangladesh, Comoros, Eritrea, France (La Reunion), India, Iran, Kenya, Maldives, Mauritius, Mozambique, Oman, Sri Lanka, South Africa, Sudan, Tanzania and Yemen. The observer states of the IOMOU are Ethiopia and Madagascar, while the observer organisations include the Black Sea Memorandum of Understanding, the Riyadh Memorandum of Understanding, the Tokyo Memorandum of Understanding, the West \& Central Africa Memorandum of Understanding, the IMO, the International Labour Organization (ILO), the United States Coast Guard, and Equasis (IOMOU, 2017). Under the Memorandum, each authority is required to establish and maintain an effective system of PSC regime. The mission of the IOMOU is "to promote the effective implementation of an improved and harmonized system of port State control by uniform application, of relevant IMO/ ILO instruments on ships operating in the region (IOMOU, 2017)."

Currently there are 10 such PSC MOUs in force including the Paris and Tokyo MOUs and the US Coast Guard which are regarded as the most efficient and effective regimes (Bateman, 2012, p. 189). The IOMOU is much less effective with certain important shipping countries in the region such as Pakistan, Madagascar, Myanmar and the Seychelles remaining outside the MOU, while many member states are not taking their role seriously (Bateman, 2012, p. 189). For instance, in 2010, four states including Bangladesh, Eritrea, Maldives and Oman did not report any inspection activity throughout the year; their subsequent record from 2011 to 2015 shows only a slight increase (IOMOU, 2017). The effectiveness of the western and Tokyo MOUs has led to many of the sub-standard ships being pushed away from Europe and America towards the Indian Ocean ports which are generally considered lax, with a few exceptions such as Australia. Thus, the ineffectiveness of the IOMOU is evidently linked to the high rate of maritime crimes in the region.

The IOMOU maintains the Indian Ocean Computerised Information System (IOCIS), a dynamic database containing comprehensive information about the global merchant fleet, various ports of 
the world, reports on ships inspections, detentions and arrests (IOMOU, 2017). The IOCIS receives data from multiple sources including commercial as well as government agencies and is thus a valuable source of intelligence for the region. The information from the IOCIS could be used by the regional coast guards, ports and custom authorities and even navies for profiling ships based on their track record of PSC inspections and detentions, a valuable input for maritime security and therefore, the IOCIS could be a vital element of a pan-Indian Ocean information grid.

\section{Regional Information Centres}

The main information centres in the Indian Ocean region are described in the following paragraphs.

Piracy Reporting Centre (PRC) of the International Maritime Bureau (IMB) at Malaysia As noted earlier, the PRC was established under the IMB, as an independent and nongovernmental agency based in Kuala Lumpur, Malaysia. It aims "to raise awareness within the shipping industry of high risk areas with pirate attacks and specific ports/anchorages where armed robberies on board ships have occurred." The PRC is a commercial venture providing free information and alerts about global maritime piracy, armed attacks on ships and other frauds and crimes related to the shipping business. The IMB itself is a specialised division of the International Chamber of Commerce (ICC) established in 1981 "to act as a focal point in the fight against all types of maritime crime and malpractice (IMB, 2017)." Thus the IMB PRC represents the commercial interests in the region aimed at tackling maritime fraud and crimes.

The Regional Cooperation Agreement on Combating Piracy and Armed Robbery against Ships in Asia (ReCAAP) Information Sharing Centre (ISC) at Singapore Following the success of the IMB PRC it was felt that PRC, which had an obvious commercial bias, tended to exaggerate the security situation in the region. This was greatly resented by the regional states which had stepped up anti-piracy efforts leading to all-round improved security scenario in the region. This promoted the idea for an alternate inter-governmental agency to monitor piracy and armed attacks on ships. Japan, as a key stakeholder in the regional security seized this opportunity and took the 
lead and helped in the formation of the ReCAAP. A proposal for combined patrols in the Strait of Malacca had been earlier mooted by Japanese prime minister Koizumi in 2001 following the "Tokyo Appeal," (a call for cooperation to combat piracy and armed robbery at sea), and the Model Action Plan of 2000, both outcomes of high level conferences on piracy and sea robbery held in Tokyo (Rahman, 2007, p. 189). An information-sharing centre was set up under ReCAAP at Malaysia in 2007. The primary aim of ReCAAP is to "analyse and prove accurate statistics of the piracy and armed robbery incidents to foster better understanding of the situation in Asia (ReCAAP, 2017)." The ReCAAP ISC reports provide a more nuanced reporting of the security incidents taking into consideration the violence factor and the economic aspects of various incidents/ crimes (ReCAAP, 2017).

The Information Fusion Centre (IFC) of the Republic of Singapore Navy As part of Singapore's strategy to foster regional collaboration in ensuring regional security, IFC was inaugurated on 27 Apr 2009. It has since evolved to become a multi-national maritime security centre with representatives from 23 countries. The primary aim of the IFC is to achieve early warning of threats through collective awareness and threat assessment, and provide actionable information for regional responses against maritime security threats. The IFC has institutionalised linkages for information sharing with over 78 agencies in 38 countries. The information received is fused into its Open And Analysed Shipping Information System (OASIS) database. The OASIS is also integrated with the Western Pacific Naval Symposium (WPNS) Regional Maritime Information Exchange and the Malacca Straits Patrols' Information System (MINDEF Singapore, 2017).

Information Management and Analysis Centre (IMAC), at Gurgaon, India This is a newly established information centre under the Indian Navy, integrating the Indian coastal radar cum automatic identification system (AIS) network (Govt. of India, MoD, 2014, p. 112). Reportedly, this network is also connected to AIS stations being setup at Sri Lanka, Maldives, Seychelles and Mauritius.

UK Maritime Trade Operations (UKMTO) The UKMTO office in Dubai administers a voluntary reporting scheme, under which merchant vessels are encouraged to send regular reports, in the piracy high risk area of the Indian Ocean region bounded by Suez, $78^{\circ}$ East and $10^{\circ}$ South. UKMTO subsequently tracks vessels and shares the information with the Combined 
Maritime Force (CMF) and E.U. headquarters (UKMTO, 2017). The UKMTO also acts as the primary point of contact for merchant vessels and liaison with military forces in the region. It is thus best suited to pass tactical information affecting commercial traffic in the region directly to the ships, rather than routing the information via company offices, thereby improving responsiveness to any incident and saving crucial time (UKMTO, 2017).

The Maritime IFC at Madagascar and Other Information Sharing Centres at Yemen, Kenya and Tanzania An IFC was established in 2015 at Antananarivo, Madagascar under the "Piracy, Maritime Awareness and Risks - Maritime Security" (PMAR-MASE) project of the E.U., aimed at building capacity for maritime domain awareness (MDA) in respect of the East and South African states and western Indian Ocean island countries (EC JRC, 2017). The E.U. has committed Euro 37 million towards improving maritime security in the region (EC, 2013). As noted earlier the new IFC was established in close collaboration with the ReCAAP and thus has many similarities with the ReCAAP ISC. The area of interest of the IFC at Madagascar includes the western Indian ocean region bounded by $20^{\circ}$ East, $76.5^{\circ}$ East, $26^{\circ}$ North and $37^{\circ}$ South. It works in close collaboration with information sharing centres (ISC) at Yemen, Kenya and Tanzania and it is manned by a team of international liaison officers from several countries (DG IFC, Madagascar, 2016).

Based on the above, it is quite clear that the Indian Ocean region has a multiplicity of information centres representing different interest groups, including commercial agencies and even extraregional powers such as Japan, United States and the E.U. that have a strategic interest in the region. It is also evident that a majority of the information centres discussed above have overlapping areas of interest. This provides ample scope for integrating the various centres into one grid. Combining all the above information centres into a common information grid accessible to all regional states as also key stakeholders including extra-regional states, could be a useful and challenging project that could possibly be done under the aegis of IORA or the IONS. India as a key regional maritime power has several bilateral information sharing agreement with a large majority of regional states for sharing of "white shipping" information and therefore could be well suited to take on a leadership role. 


\section{Potential or Futuristic Information Systems: Employment of Private Contractors for Routine Surveillance Missions}

As highlighted in the latest Indian maritime doctrine, constant intelligence, surveillance and reconnaissance are the key ingredients of MDA. However, for small island states such as Mauritius and Seychelles which have disproportionately large exclusive economic zones (EEZ) which match the size of the Indian EEZ, but which have grossly inadequate surveillance capacity; this is a formidable challenge. Consequently, they are dependent upon the Indian Navy, which has been engaged in providing ship and aircraft surveillance for both states. India has also conducted similar surveillance mission in other states. A similar effort provided by Australia in the early part of the twenty-first century, to the smaller Pacific Island States (PICs) was found unsustainable given ADFs operational commitment elsewhere as a key United States ally (Bateman \& Bergin, 2011, p. 3). This led to some states questioning Australia's commitment to regional maritime security (Bateman \& Bergin, 2011, p. 3). Thus, even though the Indian Navy has helped several littoral states in EEZ surveillance, considering the size of the area, it is unlikely that the Indian Navy would be able to sustain constant surveillance efforts outside Indian waters. The case of MV Pavit, noted earlier in the paper, highlights the overall gaps in regional surveillance efforts.

A durable and long term solution to the problem of surveillance gaps in the region could lie in a public-private partnership involving the use of commercial off the shelf (COTS) platforms including ships and aircraft provided by regional service providers and co-manned by armed forces personnel from the regional states. After all, private contractors have been employed successfully by the Royal Navy to conduct ship surveillance missions in the English Channel, and this option is also being considered by the Australian government for supporting the PICs (Bateman \& Bergin, 2011, p. 5). Furthermore, unmanned aerial systems could be another viable alternative. Unmanned systems could be provided not just for surveillance over the smaller island states but also over critical shipping lanes. The surveillance conducted by commercial platforms and unmanned vehicles could also be integrated with the other information layers to provide an additional layer of real-time information related to shipping traffic. 
Other Sources In addition to the above information layers, complementary intelligence such as satellite imagery, details of logistics facilities and medical assistance that could be deployed, could be integrated into the pan-Indian Ocean information grid in order to assist SAR and HADR operations in the region.

\section{Advantages of a pan-Indian Ocean Information Grid}

Integration of the various information centres into a common grid would help to improve MDA and also promote maritime governance in the Indian Ocean region with the various systems complementing each other to fill in the information gaps. Many of the smaller Indian Ocean littoral and island states such as Myanmar, Maldives, Mauritius and Seychelles, with limited maritime regulatory capacity to provide customs, port state control, immigration control and environmental monitoring services, could benefit from an enlarged coverage and receive up to date maritime services not otherwise available for effective maritime governance. Moreover, by networking all the sub-regional monitoring facilities, many of which are integrated with regional maritime agencies, interstate maritime coordination could be improved. This has been a major lacuna in the region, exposed during the recent loss of the Malaysian airlines flight MH 370.

A hypothetical scenario involving a collision between two tankers or even a terrorist attack on a vessel, resulting in a massive spill heading towards land with a storm warning in the area restricting SAR operations, something which could not be regarded as implausible in the Indian Ocean, would clearly would involve multiple maritime agencies of the region. Maritime accidents resulting in oil spills, can have huge environmental and economic impact, far beyond the capacity of any one state, and therefore a pan-Indian Ocean grid could synergise regional efforts and enhance interagency coordination to streamline operations. Pertinently, the EMSA, discussed below, was the outcome of the political impetus resulting from two major maritime disasters; the Erika (1999) and the Prestige (2002) accidents and the resulting oil spills which damaged thousands of kilometres of pristine Mediterranean coastline causing grave harm to the local fishing and tourism industries (EMSA, 2017). Finally, integrating the Indian Ocean states 
via an information grid would help to build mutual confidence and assist in promoting multilateralism, which is a key challenge before the regional states.

Maritime Support Services (MSS) Network by EMSA: A Model Maritime Information Grid?

The EMSA established in 2002, provides technical and scientific assistance to the European Commission (EC) and all member states on matters relating to the implementation of EC's integrated maritime policy. It is tasked with improving cooperation between, member states, providing operational assistance, including maritime services for ship monitoring and ensuring operational preparedness to tackle environmental challenges. Thus, as an operational agency of the European Union EU), "EMSA has in-depth understanding of the maritime situation in and around EU waters (EMSA, 2017)." In order to achieve a high level of maritime domain awareness, EMSA hosts multiple maritime information systems such as vessel traffic reports (LRIT, SafeSeaNet), satellite monitoring (CleanSeaNet), and Port State Control (Thetis) (EMSA, 2017). This integrated "information grid" provides all the relevant services, covering maritime safety and security, fisheries control, defence, customs, maritime law enforcement and environment protection. The maritime services are available to all member states, non-EU states and maritime institutions through the MSS network maintained by EMSA.

The EMSA is clearly a highly integrated and evolved information grid covering all European ports and maritime areas. Obviously, this is the result of an integrated maritime policy for the EU wherein all member states have agreed to share their information systems. In contrast, the Indian Ocean region is faced with multiple challenges and the regional states are yet to agree on a common maritime policy or common framework for security. Nevertheless, the MSS by EMSA provides a useful model for emulation in the Indian Ocean region in the development a panIndian Ocean information grid.

\section{Framework}


A broad framework incorporating the various sources of information is diagrammatically depicted below.

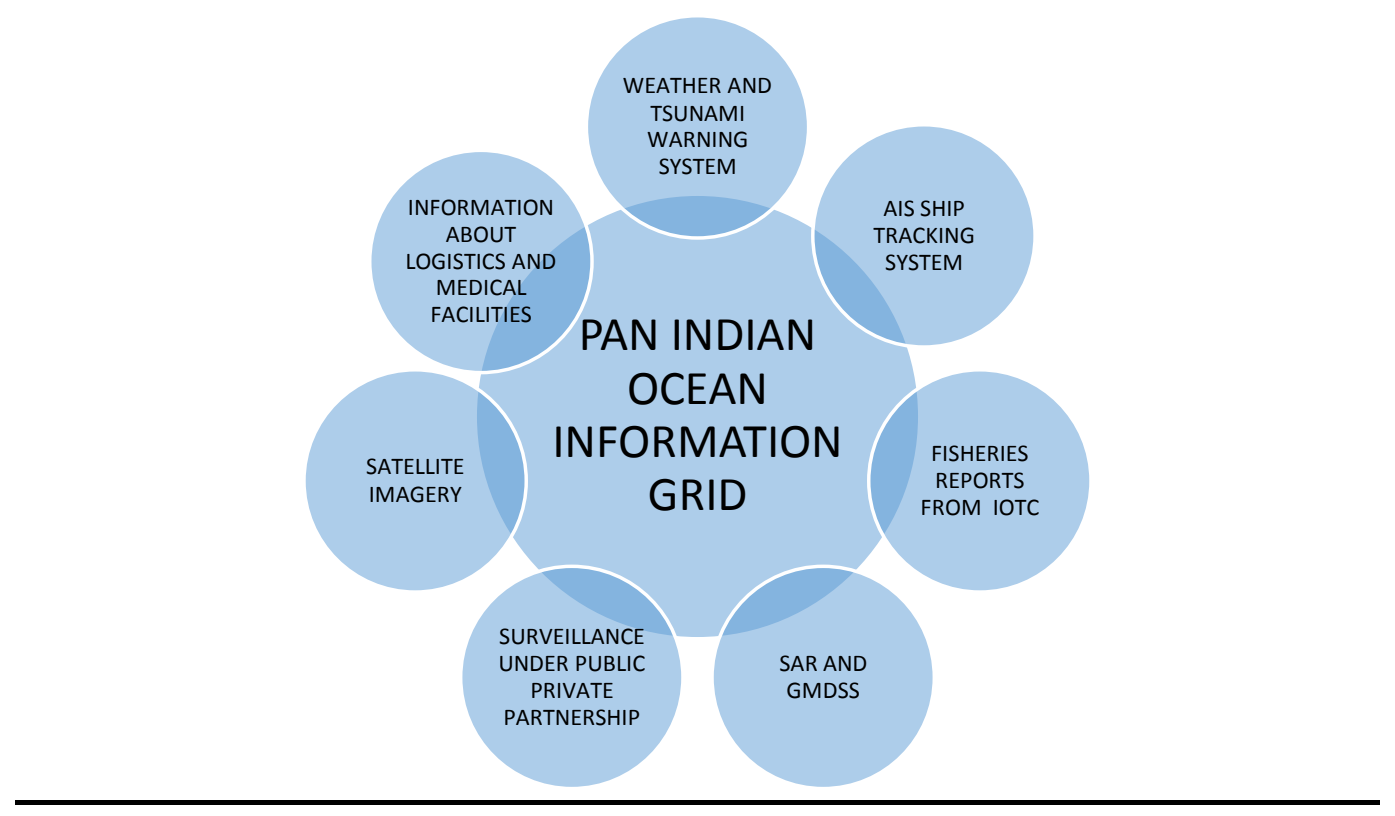

Pan-Indian Ocean Information Grid

\section{Building Consensus for a pan-Indian Ocean Information Grid: Emulating the "Cooperative Mechanism" in the Straits of Malacca and Singapore}

A key challenge in establishing a Pan-Indian Ocean information grid would be to involve all the principal stakeholders including extra-regional states with strategic interests, and the shipping industry with commercial interests in the region. Clearly, this is no easy task given the lack of political alignment and mutual mistrust amongst several key regional states. A similar predicament of bringing together multiple interest groups and stakeholders under one common mechanism was faced by the Southeast Asian states, which were grappling with a spurt in armed attacks on ships in the early years of the twenty-first century. This problem was addressed in September 2007 by the creation of the "cooperative mechanism on safety of navigation and environment protection in the straits of Malacca and Singapore," or the Cooperative Mechanism, 
which reconciled the disparate interests of various stakeholders including extra-regional user states such as Australia, China, India and Japan, and major shipping companies. The Cooperative Mechanism was facilitated by the IMO and included various projects aimed at promoting navigational safety, ship security and environmental protection in the Singapore and Malacca Straits (Cooperative Mechanism, 2017).

The cooperative mechanism functions directly under a Tripartite Technical Experts Group (TTEG) jointly led by the three littoral states and includes three constituents namely: the Cooperation Forum comprising all the user states; the shipping industry and other stakeholders; a Project Coordination Committee consisting of the littoral states and project sponsors to oversee the coordination and implementation of various projects; and the Aids to Navigation Fund for receiving direct financial contributions from all the parties for installation and maintenance of aids to navigation in the Straits of Malacca and Singapore (Cooperative Mechanism, 2017).

The success of the Cooperative Mechanism lies in the fact that it brought together various stakeholders onto a common platform where they could voice their apprehensions or views on various aspects of maritime safety and security in the region. At the same time, it has permitted the littoral states to maintain strategic autonomy in the regional affairs. The Cooperative Mechanism is thus a useful approach that could be adopted in the Indian Ocean, and a similar initiative led by key regional states such as Australia, India, Indonesia, Iran, Saudi Arabia, Singapore, South Africa and Pakistan could be examined under the aegis of the Indian Ocean Rim Association and Indian Ocean Naval Symposium. The regional states could be brought together into one Regional Experts Group mimicking the TTEG to oversee all aspects of information sharing involving extra- regional partners and other stakeholders, while an Indian Ocean "Cooperative Forum" comprising all the relevant partners in maritime security in the Indian Ocean, such as the United States, China and Japan, and the shipping industry, could serve as the platform for discussions on issues of common interest as well as exchange of information.

\section{Infrastructure}

The extant infrastructure for information sharing in the region in the form of various information centres, which are already integrated to the various maritime agencies at the sub-regional level, makes it easy to create a functional pan-Indian Ocean information grid in a short period, with 
minor upgradations or improvements. Further, recent advances in commercial technologies such as "big data analytics" and "enterprise resource planning" tools and platforms that have allowed large global organisations to integrate multiple sources of data, bringing together disparate pieces of information into a unified environment, provide readymade options. Such solutions have been used successfully across multiple sectors such as urban transportation systems, ports and shipping, disaster planning and healthcare services. Thus, by incorporating commercial technologies, a state-of-art pan Indian Ocean information grid could be developed for use by the entire region.

\section{Funding}

The upgrading of existing infrastructure, the use of private contractors to carry out regular aerial and ship surveillance missions by private contractors and the creation and maintenance of a panIndian Ocean information grid will obviously incur significant costs. Once again, instead of creating a new venture, the Special Fund under the IORA could be used for this purpose. The Special Fund was created in 2008, has been financed by contributions from all member states, dialogue partners and observers. The total fund corpus is presently limited, totaling over $\$ 2$ million with India being the largest donor with a total contribution of $\$ 1,050,000$, followed by the U.A.E. with a contribution of $\$ 500,000$, and China with a total contribution of $\$ 200,000$ (IORA, 2015). Many leading dialogue partners such as France, Japan, United States and the U.K. have evidently not contributed to the fund. So far, over six projects have been undertaken utilising about $\$ 165,000$ from the IORA Special Fund, covering areas such as tourism, fisheries, tsunami and science and technology. Clearly, limited funding has precluded planning for largescale projects of strategic significance to the entire region. By opening the Special Fund to all stakeholders in the Indian Ocean including the user states, the maritime industry and even banks such as the Asian Infrastructure Investment Bank (AIIB), created to fund the China's ambitious “One Belt One Road” project, a large corpus for undertaking various projects could be created. The Special Fund could be administered by the Regional Experts Group with various contributors being allowed as observers.

\section{Conclusion}


Connecting the various information systems in the Indian Ocean region could help to build comprehensive maritime domain awareness and promote effective maritime governance by addressing current gaps and overlaps in MDA, as described in this paper. This could be taken up by all the regional states, in collaboration with other interest groups and stakeholders under the extant regional fora. A definitive mechanism for creating a pan-Indian Ocean information grid taking into consideration the unique attributes of the region is certainly a worthwhile area for further research, which is outside the scope of the current paper. However the Cooperative Mechanism of Southeast Asia is an idea worth pursuing, and the EMSA, which has successfully integrated multiple maritime agencies in Europe to provide common services, also serves as a useful functional model for policymakers to consider. The existing regional infrastructure allows for rapid integration of the multiple information centres into a pan-Indian Ocean information grid with funding from littoral states and other stakeholders. Also, commercial off the shelf technology allows for integration of diverse information layers including all sub-regional information facilities as also futuristic surveillance systems such as unmanned platform sensors and satellite imagery on to a common platform. Finally, the pan-Indian Ocean information grid could serve as a common thread that binds the Indian Ocean region into a cohesion framework and thus provide the base upon which a comprehensive regional security regime could be built.

\section{References:}

AMSA (2001), Australian Search and Rescue Region, available at https://www.amsa.gov.au/search-andrescue/sar-in-australia/arrangements-in-australia.html - accessed on 26 January 2017.

AMSA (2017), Australian Maritime Safety Authority website, available at https://www.amsa.gov.au accessed on 10 February 2017.

Bateman, Sam (2012), "Maritime security and port state control in the Indian Ocean Region", Journal of the Indian Ocean Region, Vol. 8, No. 2, pp. 188-201.

Bateman, Sam and Bergin, Anthony (2011), Staying the Course: Australia and maritime security in the South Pacific, Strategic Insight, ASPI, Canberra, p. 3.

Bremner Lindsay (2015), Fluid ontologies in the search for MH370, Journal Of The Indian Ocean Region, Vol. 11 , Issue No. 1, pp. 10-12. 
Cooperation Forum website, available at http://www.cm-soms.com - accessed on 12 February 2017.

Cooperative Mechanism (2017), Aids to Navigation Fund, available at http://www.cm-

soms.com/index.php?p=ext-page\&id=4\&ep=1.html - accessed on 13 February 2017.

CSCAP (2016), Second Meeting of the CSCAP Study Group on Harmonisation of Aeronautical and

Maritime Search and Rescue (SAR), available at http://www.cscap.org/uploads/docs/SAR/2SARCo-

ChairsReportApr2016.pdf - accessed on 12 February 2017.

Director General of IFC Madagascar, Maritime Information Fusion Centre of Madagascar Project, 26

February 2016.

European Commission (2013), EU to provide over $€ 37$ million to fight piracy in Eastern and Southern Africa, available at https://ec.europa.eu/europeaid/news-and-events/eu-provide-over-eu37-millionfight-piracy-eastern-and-southern-africa en - accessed on 10 January 2017.

European Commission Joint Research Centre (2017), Piracy, Maritime Awareness and Risks, available at https://ec.europa.eu/jrc/en/research-topic/piracy-maritime-awareness-and-risks.html - accessed on 17 February 2017.

European Maritime Safety Agency (EMSA) (2017), Integrating data for a more safe, secure and clean maritime environment, available at http://www.emsa.europa.eu/.html - accessed on 14 February 2017.

Government of India, Ministry of Defence (2014), Annual Report 2015, New Delhi, p. 112.

Greenpeace International (2013), Indian Ocean Tuna Commission - Where To From Here, available at http://www.greenpeace.org/africa/en/News/Blog/indian-ocean-tuna-commission-where-to-fromhe/blog/45111/ - accessed on 12 January 2017.

Guha-Sapir, D., Hoyois, Philippe and Below, Regina (2015), Annual Disaster Statistical Review 2014: The numbers and trends, CRED, Brussels, September 2015, pp. 1-2.

IMB (2017), International Maritime Bureau website, available at https://www.icc-ccs.org/icc/imb.html accessed on 20 February. 
IMO (1999), Shipping Emergencies - Search and Rescue and the GMDSS, available at http://www.imo.org/en/OurWork/Safety/Regulations/Documents/GMDSSandSAR1999.pdf, accessed on 15 January 2017.

IMO (2007), Milestone Agreement Reached on Co-operation over the Straits of Malacca and Singapore, Briefing No. 29/2007, available at http://www.imo.org/Newsroom/mainframe.asp?topic id=1472\&doc - accessed on 15 January 2017.

IMO (2017), International Maritime Organisation website, available at http://www.imo.org - accessed on 1 February 2017.

Indian National Centre for Ocean Information Services (INCOIS) (2017) website, available at http://www.incois.gov.in/portal/index.jsp - accessed on 20 February 2017.

Indian Ocean Rim Association (IORA) (2017) website, available at http://www.iora.net/ - accessed on 24 February 2017.

Indian Ocean Tsunami Warning System (IOTWS) website, available at http://iotic.ioc-unesco.org/indianocean-tsunami-warning-system/16/what-is-iotws - accessed on 20 January 2017.

Integrated Headquarters (IHQ) of the Ministry of Defence(MoD) Navy (2016), Indian Maritime Doctrine, Indian Navy Naval Strategic Publication 1.1, New Delhi, p. 75.

International Convention on Maritime Search and Rescue (SAR Convention), Hamburg, 27 April 1979.

IOMOU (2017), Indian Ocean Memorandum of Understanding on Port State Control website, available at: http://www.iomou.org - accessed on 22 January 2017.

IORA (2014), Final Communique 14th Meeting of the Council of Ministers of the Indian Ocean Rim Association Perth Communiqué, available at http://www.iora.net/media/151273/communiqu final.pdf - accessed on 23 February 2017.

IORA (2015), Indian Ocean Rim Association website, Special Fund, available at http://www.iora.net/projects/special-fund/special-fund.aspx - accessed on 2 February 2017. 
IOTC (2017), Indian Ocean Tuna Commission website, available at http://www.iotc.org - accessed on 22 February 2017.

MINDEF (2009), Ministry of Defence, Singapore, Inauguration of the Information Fusion Centre (IFC), available at

http://www.mindef.gov.sg/imindef/press room/official releases/nr/2009/apr/27apr09 $\mathrm{nr}$.html\#.Vsprlf $\underline{|96 U|}$ - accessed on 14 February 2017.

Ministry of Foreign Affairs of Japan, Entry into Force of the Regional Cooperation Agreement on Combating Piracy and Armed Robbery against Ships in Asia (ReCAAP), 4 September 2006.

NDTC (2011), Another ship stuck at Mumbai's Juhu beach, available at http://www.ndtv.com/mumbainews/another-ship-stuck-at-mumbais-juhu-beach-463454 - accessed on 24 Feb 2017.

Rahman, Chris (2007), "The International Politics of Combating Piracy in Southeast Asia," in Peter Lehr, Violence at Sea: Piracy in the Age of Global Terrorism, Routledge, London, p. 184.

ReCAAP (2017), available at http://www.recaap.org/AboutReCAAPISC.aspx.html - accessed on 13 January 2017.

Sakhuja, Vijay (2014)," Indian Ocean and the IORA: Search and Rescue Operations," IPCS Commentary No:4724, p. 3.

Sampan Panjarat (2009), "The Tuna Resource Management in the Indian Ocean: the Challenges for the Indian Ocean Tuna Commission," available at http://www.un.org/depts/los/nippon/unnff_programme_home/alumni/tokyo_alumni_presents_files/al um_tokyo_panjarat.pdf - accessed on 25 February 2017.

UKMTO (2017), UK Maritime Transport Office Wesbite, accessed on 24 February 2017 at http://www.mschoa.org/on-shore/links.html

United States Navy (2007), Navy Maritime Domain Awareness Concept, Washington, pp. 3-5.

Western and Central Pacific Fisheries Commission (WCPFC) website available at https://www.wcpfc.int/accessed on 23 February 2017. 
Young, Jim (2015), Regional Cooperation in Search and Rescue (SAR) Operations - An Australian

Perspective, IORA Dialogue 2015, available at

http://www.iora.net/media/158588/8. john young presentation.pdf accessed on 30 January 2017. 